\title{
Enhancing togetherness: kinetochores and cohesion
}

\author{
Jennifer L. Gerton ${ }^{1}$ \\ Stowers Institute for Medical Research and University of Kansas Medical Center, Kansas City, Missouri 64110, USA
}

All organisms must correctly copy and equally distribute their genetic information each and every time a new cell is created. In eukaryotic cells, this action involves many different coordinated processes, including DNA replication, kinetochore and spindle formation, and chromosome cohesion. If errors occur in chromosome segregation, a chromosome may be lost or gained, resulting in an aneuploid cell. Aneuploidy is associated with cancer in humans, as well as a variety of developmental disorders including Downs syndrome. Because all organisms require the faithful transmission of their genetic information, many of these processes and proteins are evolutionarily conserved. Thus, gaining a basic understanding of the basic mechanisms that contribute to the accurate segregation of chromosomes is essential for understanding the underlying cause of some human diseases.

The kinetochore is a complex multiprotein structure that forms at centromeres (for recent reviews, see McAinsh et al. 2003; Meraldi et al. 2006). The basic function of the kinetochore is to attach chromosomes to microtubules. Once attached, microtubules can then pull chromosomes to opposite spindle poles, thus enabling the physical separation of chromosomes into two cells. Kinetochores can consist of 70 proteins or more, which are often divided up into three layers: inner, central, and outer. The inner proteins are associated with the DNA and are linked to the outer layer by the central layer. The outer kinetochore proteins attach to microtubules and associate with several checkpoint proteins that monitor various aspects of kinetochore and spindle formation.

Accurate attachment of kinetochores to microtubules is referred to as amphitelic attachment and refers specifically to the case in which one sister kinetochore is attached to microtubules emanating from one spindle pole and the second sister kinetochore is attached to microtubules from the other spindle pole (Fig. 1A). This situation is often referred to as biorientation. In some cases, the attachment between kinetochores and microtubules can be defective. The attachment can be monooriented, meaning that microtubules from only one of the two poles are involved in the attachment. There are

\footnotetext{
${ }^{1}$ Correspondence.
}

E-MAIL jeg@stowers-institute.org; FAX (816) 926-2094

Article is online at http://www.genesdev.org/cgi/doi/10.1101/gad.1523107. two different cases of this: syntelic and monotelic. In syntelic attachment, both sister kinetochores are attached to microtubules from the same pole (Fig. 1B). In monotelic attachment, one of the kinetochores may be attached to microtubules from one pole and the other kinetochore is unattached (Fig. 1C). In a merotelic attachment, one kinetochore may be attached to microtubules from both poles. This occurs in organisms that have multiple microtubules attached to a single kinetochore. Defects in kinetochore attachment may lead to the activation of the spindle checkpoint.

All eukaryotic cells studied to date have a mitotic spindle checkpoint. This refers to the fact that defects in the mitotic spindle trigger a cascade of events that lead to cell cycle delay or arrest. Defects that activate the checkpoint likely include both (1) a lack of kinetochoremicrotubule attachment and (2) a lack of tension between sister kinetochores (Fig. 1D; for a recent review, see Pinsky and Biggins 2005). Despite ongoing debate, there is a good body of evidence accumulating that lack of tension can trigger the spindle checkpoint in budding yeast. The protein with the best evidence of being involved in tension sensing is Aurora kinase B, or Ipl1 in budding yeast (Biggins and Murray 2001; Stern and Murray 2001 ).

In the presence of functional Ipll, defective kinetochore-microtubule attachments are detached, presumably to allow for an increased chance at forming correct attachments (Tanaka et al. 2002; Pinsky et al. 2006). An Ipl1 mutant (ip11-321) displays 85\% chromosome missegregation following a G1 arrest (Biggins et al. 1999). These missegregation events in many cases appear to be due to syntelic attachments since sister chromatids are observed segregating to the same spindle pole (Biggins et al. 1999; Tanaka et al. 2002). Since syntelic attachments do not generate tension, this Ipll mutant will lack tension.

In mitotic rat PtK cells, the kinetochore is attached to an average of 24 microtubules each and in grasshopper spermatocytes, the average is 32 (McEwen et al. 1997; King and Nicklas 2000). The situation in budding yeast is considerably simpler. Each kinetochore attaches to a single microtubule (Winey et al. 1995). Thus, each kinetochore exists in one of two states, attached or unattached, and there can be no partial microtubule occu- 


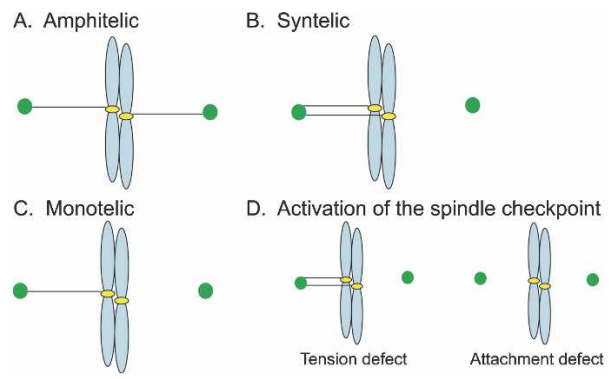

Figure 1. Kinetochore-microtubule attachments. Chromosomes are shown in blue, centromeres in yellow, microtubules in black, and spindle poles in green. (A) Amphitelic attachment: Each kinetochore is attached to microtubules from opposing spindle poles. (B) Syntelic attachment: Both sister kinetochores are attached to microtubules from the same spindle pole. $(C)$ Monotelic attachment: One kinetochore is attached to a microtubule from a spindle pole and the other kinetochore is not attached to a microubule. $(D)$ Activation of the spindle checkpoint can occur via a tension defect or an attachment defect.

pancy that could generate "degrees" of tension or attachment. This makes budding yeast an ideal simplified model for the study of kinetochores and microtubules.

Since tension implies two opposing forces, how would a lack of tension be generated? In the case of the mitotic spindle checkpoint, there is the activity that keeps sister chromatids together and the activity that pulls them apart. The force that keeps sister chromatids together is chromosome cohesion, as mediated by the cohesin complex. In fact, there is an intense region of association of this complex at pericentric domains that spans $20-50 \mathrm{~kb}$ that is needed for accurate segregation of sister chromatids in yeast (Blat and Kleckner 1999; Megee et al. 1999; Tanaka et al. 1999; Glynn et al. 2004; Lengronne et al. 2004; Weber et al. 2004). The force that pulls sister chromatids apart is their attachment to the plus end of microtubules via the kinetochore.

The cohesin complex itself is composed of four subunits: Smc1, Smc3, Scc1/Mcd1, and Scc3. The Smc proteins (structural maintenance of chromosomes) contain intramolecular coiled-coils that form a $\mathrm{V}$ shape with sides that are $50 \mathrm{~nm}$ long (Anderson et al. 2002; Haering et al. 2002). The folding of the coils brings the $\mathrm{N}$ and $\mathrm{C}$ termini together, and these domains are held together by Scc1/Mcd1. Scc3 binds to Scc1/Mcd1. Together these subunits appear to form a ring structure (Haering et al. 2002). Cleavage of the Scc1/Mcd1 subunit by the protease separase allows the ring to come apart (Uhlmann et al. 1999).

The exact nature of how the complex holds sisters together is a matter of debate. The nature of the interaction of the complex with chromatin becomes especially relevant at centromeric regions. While one model contends that the complex forms a ring that embraces two sister chromatids (Haering et al. 2002; Gruber et al. 2003), this model is difficult to reconcile with the observation that centromeres appear to go through cycles of separation and rejoining during metaphase that do not require cohesin proteolysis, and the distance of their separation (up to $0.8 \mu \mathrm{m}$ ) is too great for the embrace model to accommodate (Fig. 2A; He et al. 2000). Alternate proposals for the structure of cohesin have been made that can account for the separation of centromeres, including individual rings around each chromatid that can interact and come apart (Fig. 2B; Milutinovich and Koshland 2003; Losada and Hirano 2005), or even a conversion of intersister complexes to intrasister complexes at pericentric regions (Fig. 2C; Bloom et al. 2006).

In this issue of Genes and Development, Eckert et al. (2007) provide evidence that the inner kinetochore, in particular the centromere-specific histone $\mathrm{H} 3$ variant Cse4, is necessary to recruit the cohesin complex to pericentric domains in response to a lack of tension. In previous work, (Weber et al. 2004) a second inner kinetochore protein, Ndc10, was also shown to be required to enhance pericentric cohesin association in the absence of tension. In another study, (Collins et al. 2006) a mutation in Cse4 (cse4-353) was found to result in a sister kinetochore biorientation defect, but cohesin levels at the centromere were not affected. However, this particular Cse 4 mutant does not locate to centromeres, and the experiment was done in a manner such that wild-type Cse4 may still be present at centromeres and kinetochores are somewhat intact albeit defective, arguing that the enhancer effect of the inner kinetochore occurs in cis, as was suggested by an earlier study (Weber et al. 2004).

Eckert et al. (2007) also propose that the association of cohesin at pericentric regions is in equilibrium with disassociation caused by the tension exerted on bioriented

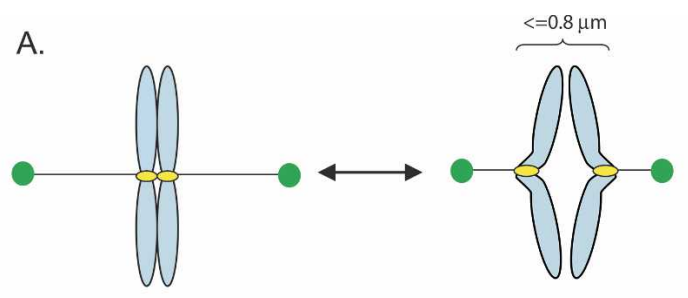

B.

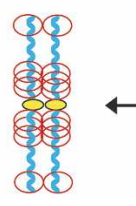

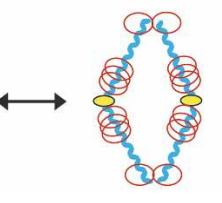

C.

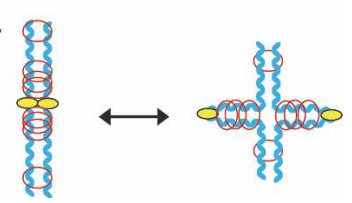

Figure 2. The cohesin complex and sister centromere separation. DNA is shown in blue; centromeres are indicated in yellow. (A) Sister centromeres in metaphase have been observed to separate up to $0.8 \mu \mathrm{m}$ before reuniting. This occurs in the absence of cohesin proteolysis (He et al. 2000). In contrast, sites in chromosome arms remain joined. Microtubules are shown in black and spindle poles in green. (B) If sister chromosomes are cohesed by two cohesin rings (red circles) that interact, these protein-protein interactions may be transiently dissociated by the pulling force of the microtubules in the neighborhood of centromeric chromatin. $(C)$ If sister chromosomes are cohesed by a single cohesin ring (red circles), these rings may convert to intrastrand linkages in the neighborhood of centromeric chromatin. 
kinetochores. The outer components of the kinetochore are required for this process since they sense tension, a lack of which increases cohesin association. In particular, in an ipl1 mutant background (ip11-321) in which tension is defective due to an increase in syntelic attachments, pericentric cohesin association is increased. Similar results were obtained in a stu2-277 background, which is also expected to reduce tension without eliminating attachment. Stu2, an essential outer kinetochore protein, normally helps to generate force on chromosomes by facilitating the depolymerization of microtubules (van Breugel et al. 2003).

While the results of Eckert et al. (2007) provide a clear indication that the kinetochore is required for cohesin association and a lack of tension serves to enhance pericentromeric cohesion, they also highlight new questions. For instance, what is the molecular mechanism of the enhancer activity? Are there protein-protein interactions between kinetochore components and cohesin? How does tension generated at the kinetochore cause the loading of cohesin within a 20-50 kb domain? Resolving the structure of the cohesin complex relative to pericentric regions will be one necessary step toward shedding light on these issues.

There are other instances in which a relatively short DNA element can act over large chromosomal domains, namely, telomeric silencing (Renauld et al. 1993; Hecht et al. 1996) and X-chromosome inactivation (Lee et al. 1999). Interestingly, these are both phenomenon of transcriptional repression. In the case of Sir-mediated silencing, the model is that the silencing complex initially binds to a specific DNA element and then the histone deacetylation activity of the complex acts on H3-K9, H3$\mathrm{K} 14$, and H4-K16 in neighboring regions, allowing the "spreading" of silencing to occur. Methylated Lys 9 of histone $\mathrm{H} 3$ is a modification commonly associated with heterochromatin, and this modification allows for the association of Swi6 (HP-1 homolog) with centromeric regions in fission yeast, which has in turn been shown to contribute to the recruitment of cohesin to pericentric regions (Bernard et al. 2001; Nonaka et al. 2002). Although budding yeast lacks a clear homolog of HP-1, it may contain pericentric histone modifications or histone variants that facilitate cohesin association.

Sequences that can nucleate the binding of the dosage compensation complex for X inactivation in Caenorhabditis elegans have recently been discovered (McDonel et al. 2006). The mechanism by which transcriptional repression extends from these DNA elements appears to be due to binding to particular sequences followed by shortand long-range spreading of the complex that leads to transcriptional repression (Csankovszki et al. 2004). The dosage compensation complex in C. elegans contains two subunits that belong to the Smc family, suggesting Smc proteins may share a common mechanism for "spreading," once their association has been nucleated.

The results of Eckert et al. (2007) also suggest that pericentric cohesion is more important for chromosome segregation than arm cohesion. This observation is in keeping with two results: (1) In vertebrate cells, arm co- hesion is dissolved in prophase (and chromosomes still segregate accurately) (Hauf et al. 2005). (2) In meiosis, arm cohesion is dissolved prior to the first meiotic division (and chromosomes still segregate accurately at the second meiotic division) (Watanabe and Nurse 1999; Buonomo et al. 2000). If cohesion at centromeres is sufficient, at least in some cases, to promote accurate chromosome segregation, one has to ask the importance of arm cohesion whose role in chromosome segregation may be secondary to roles in DNA repair (Strom et al. 2004; Unal et al. 2004), chromosome condensation (Hartman et al. 2000; Lavoie et al. 2002), or even transcription (Rollins et al. 1999), but this is a question that remains to be answered definitively.

\section{Acknowledgments}

I thank Paul Megee for communicating unpublished results. I thank the Gerton laboratory for comments on the manuscript. I am supported by the Stowers Institute for Medical Research.

\section{References}

Anderson, D.E., Losada, A., Erickson, H.P., and Hirano, T. 2002. Condensin and cohesin display different arm conformations with characteristic hinge angles. J. Cell Biol. 156: 419-424.

Bernard, P., Maure, J.F., Partridge, J.F., Genier, S., Javerzat, J.P., and Allshire, R.C. 2001. Requirement of heterochromatin for cohesion at centromeres. Science 294: 2539-2542.

Biggins, S. and Murray, A.W. 2001. The budding yeast protein kinase Ipl1/Aurora allows the absence of tension to activate the spindle checkpoint. Genes \& Dev. 15: 3118-3129.

Biggins, S., Severin, F.F., Bhalla, N., Sassoon, I., Hyman, A.A., and Murray, A.W. 1999. The conserved protein kinase Ipl1 regulates microtubule binding to kinetochores in budding yeast. Genes \& Dev. 13: 532-544.

Blat, Y. and Kleckner, N. 1999. Cohesins bind to preferential sites along yeast chromosome III, with differential regulation along arms versus the centric region. Cell 98: 249-259.

Bloom, K., Sharma, S., and Dokholyan, N.V. 2006. The path of DNA in the kinetochore. Curr. Biol. 16: R276-R278.

Buonomo, S.B., Clyne, R.K., Fuchs, J., Loidl, J., Uhlmann, F., and Nasmyth, K. 2000. Disjunction of homologous chromosomes in meiosis I depends on proteolytic cleavage of the meiotic cohesin Rec8 by separin. Cell 103: 387-398.

Collins, K.A., Camahort, R., Seidel, C., Gerton, J.L., and Biggins, S. 2006. The overexpression of a Saccharomyces cerevisiae centromeric histone $\mathrm{H} 3$ variant mutant protein leads to a defect in kinetochore biorientation. Genetics [Epub December 6, 2006; 10.1534/genetics.106.064410].

Csankovszki, G., McDonel, P., and Meyer, B.J. 2004. Recruitment and spreading of the C. elegans dosage compensation complex along X chromosomes. Science 303: 1182-1185.

Eckert, C.A., Gravdahl, D.J., and Megee, P.C. 2007. The enhancement of pericentromeric cohesin association by conserved kinetochore components promotes high-fidelity chromosome segregation and is sensitive to microtubule-based tension. Genes \& Dev. (this issue).

Glynn, E.F., Megee, P.C., Yu, H.G., Mistrot, C., Unal, E., Koshland, D.E., DeRisi, J.L., and Gerton, J.L. 2004. Genome-wide mapping of the cohesin complex in the yeast Saccharomyces cerevisiae. PLoS Biol. 2: E259.

Gruber, S., Haering, C.H., and Nasmyth, K. 2003. Chromosomal 
cohesin forms a ring. Cell 112: 765-777.

Haering, C.H., Lowe, J., Hochwagen, A., and Nasmyth, K. 2002. Molecular architecture of SMC proteins and the yeast cohesin complex. Mol. Cell 9: 773-788.

Hartman, T., Stead, K., Koshland, D., and Guacci, V. 2000. Pds5p is an essential chromosomal protein required for both sister chromatid cohesion and condensation in Saccharomyces cerevisiae. J. Cell Biol. 151: 613-626.

Hauf, S., Roitinger, E., Koch, B., Dittrich, C.M., Mechtler, K., and Peters, J.M. 2005. Dissociation of cohesin from chromosome arms and loss of arm cohesion during early mitosis depends on phosphorylation of SA2. PLOS Biol. 3: e69.

He, X., Asthana, S., and Sorger, P.K. 2000. Transient sister chromatid separation and elastic deformation of chromosomes during mitosis in budding yeast. Cell 101: 763-775.

Hecht, A., Strahl-Bolsinger, S., and Grunstein, M. 1996. Spreading of transcriptional repressor SIR3 from telomeric heterochromatin. Nature 383: 92-96.

King, J.M. and Nicklas, R.B. 2000. Tension on chromosomes increases the number of kinetochore microtubules but only within limits. J. Cell Sci. 113: 3815-3823.

Lavoie, B.D., Hogan, E., and Koshland, D. 2002. In vivo dissection of the chromosome condensation machinery: Reversibility of condensation distinguishes contributions of condensin and cohesin. J. Cell Biol. 156: 805-815.

Lee, J.T., Lu, N., and Han, Y. 1999. Genetic analysis of the mouse $\mathrm{X}$ inactivation center defines an $80-\mathrm{kb}$ multifunction domain. Proc. Natl. Acad. Sci. 96: 3836-3841.

Lengronne, A., Katou, Y., Mori, S., Yokobayashi, S., Kelly, G.P., Itoh, T., Watanabe, Y., Shirahige, K., and Uhlmann, F. 2004. Cohesin relocation from sites of chromosomal loading to places of convergent transcription. Nature 430: 573-578.

Losada, A. and Hirano, T. 2005. Dynamic molecular linkers of the genome: The first decade of SMC proteins. Genes \& Dev. 19: $1269-1287$.

McAinsh, A.D., Tytell, J.D., and Sorger, P.K. 2003. Structure, function, and regulation of budding yeast kinetochores. Annu. Rev. Cell Dev. Biol. 19: 519-539.

McDonel, P., Jans, J., Peterson, B.K., and Meyer, B.J. 2006. Clustered DNA motifs mark $\mathrm{X}$ chromosomes for repression by a dosage compensation complex. Nature 444: 614-618.

McEwen, B.F., Heagle, A.B., Cassels, G.O., Buttle, K.F., and Rieder, C.L. 1997. Kinetochore fiber maturation in PtK1 cells and its implications for the mechanisms of chromosome congression and anaphase onset. J. Cell Biol. 137: $1567-1580$.

Megee, P.C., Mistrot, C., Guacci, V., and Koshland, D. 1999. The centromeric sister chromatid cohesion site directs Mcdlp binding to adjacent sequences. Mol. Cell 4: 445-450.

Meraldi, P., McAinsh, A.D., Rheinbay, E., and Sorger, P.K. 2006. Phylogenetic and structural analysis of centromeric DNA and kinetochore proteins. Genome Biol. 7: R23.

Milutinovich, M. and Koshland, D.E. 2003. Molecular biology. SMC complexes-Wrapped up in controversy. Science 300: $1101-1102$.

Nonaka, N., Kitajima, T., Yokobayashi, S., Xiao, G., Yamamoto, M., Grewal, S.I., and Watanabe, Y. 2002. Recruitment of cohesin to heterochromatic regions by Swi6/HP1 in fission yeast. Nat. Cell Biol. 4: 89-93.

Pinsky, B.A. and Biggins, S. 2005. The spindle checkpoint: Tension versus attachment. Trends Cell Biol. 15: 486-493.

Pinsky, B.A., Kung, C., Shokat, K.M., and Biggins, S. 2006. The Ipl1-Aurora protein kinase activates the spindle checkpoint by creating unattached kinetochores. Nat. Cell Biol. 8: 7883.

Renauld, H., Aparicio, O.M., Zierath, P.D., Billington, B.L.,
Chhablani, S.K., and Gottschling, D.E. 1993. Silent domains are assembled continuously from the telomere and are defined by promoter distance and strength, and by SIR3 dosage. Genes \& Dev. 7: 1133-1145.

Rollins, R.A., Morcillo, P., and Dorsett, D. 1999. Nipped-B, a Drosophila homologue of chromosomal adherins, participates in activation by remote enhancers in the cut and Ultrabithorax genes. Genetics 152: 577-593.

Stern, B.M. and Murray, A.W. 2001. Lack of tension at kinetochores activates the spindle checkpoint in budding yeast. Curr. Biol. 11: 1462-1467.

Strom, L., Lindroos, H.B., Shirahige, K., and Sjogren, C. 2004 Postreplicative recruitment of cohesin to double-strand breaks is required for DNA repair. Mol. Cell 16: 1003-1015.

Tanaka, T., Cosma, M.P., Wirth, K., and Nasmyth, K. 1999. Identification of cohesin association sites at centromeres and along chromosome arms. Cell 98: 847-858.

Tanaka, T.U., Rachidi, N., Janke, C., Pereira, G., Galova, M., Schiebel, E., Stark, M.J., and Nasmyth, K. 2002. Evidence that the Ipl1-Sli15 (Aurora kinase-INCENP) complex promotes chromosome bi-orientation by altering kinetochorespindle pole connections. Cell 108: 317-329.

Uhlmann, F., Lottspeich, F., and Nasmyth, K. 1999. Sister-chromatid separation at anaphase onset is promoted by cleavage of the cohesin subunit Scc1. Nature 400: 37-42.

Unal, E., Arbel-Eden, A., Sattler, U., Shroff, R., Lichten, M., Haber, J.E., and Koshland, D. 2004. DNA damage response pathway uses histone modification to assemble a doublestrand break-specific cohesin domain. Mol. Cell 16: 991-1002.

van Breugel, M., Drechsel, D., and Hyman, A. 2003. Stu2p, the budding yeast member of the conserved Dis1/XMAP215 family of microtubule-associated proteins is a plus end-binding microtubule destabilizer. J. Cell Biol. 161: 359-369.

Watanabe, Y. and Nurse, P. 1999. Cohesin Rec8 is required for reductional chromosome segregation at meiosis. Nature 400: 461-464.

Weber, S.A., Gerton, J.L., Polancic, J.E., DeRisi, J.L., Koshland, D., and Megee, P.C. 2004. The kinetochore is an enhancer of pericentric cohesin binding. PLOS Biol. 2: E260.

Winey, M., Mamay, C.L., O'Toole, E.T., Mastronarde, D.N., Giddings Jr., T.H., McDonald, K.L., and McIntosh, J.R. 1995. Three-dimensional ultrastructural analysis of the Saccharomyces cerevisiae mitotic spindle. J. Cell Biol. 129: 16011615 . 


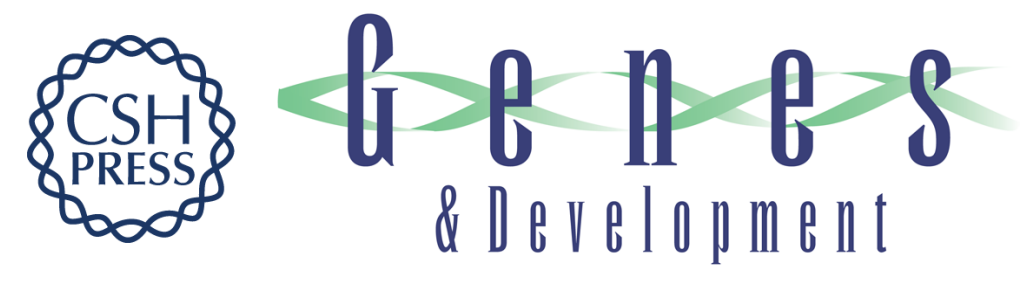

\section{Enhancing togetherness: kinetochores and cohesion}

Jennifer L. Gerton

Genes Dev. 2007, 21:

Access the most recent version at doi:10.1101/gad.1523107

Related Content The enhancement of pericentromeric cohesin association by conserved kinetochore components promotes high-fidelity chromosome segregation and is sensitive to microtubule-based tension

Carrie A. Eckert, Daniel J. Gravdahl and Paul C. Megee

Genes Dev. February , 2007 21: 278-291

References This article cites 41 articles, 16 of which can be accessed free at: http://genesdev.cshlp.org/content/21/3/238.full.html\#ref-list-1

Articles cited in:

http://genesdev.cshlp.org/content/21/3/238.full.html\#related-urls

License

Email Alerting Receive free email alerts when new articles cite this article - sign up in the box at the top

Service right corner of the article or click here.

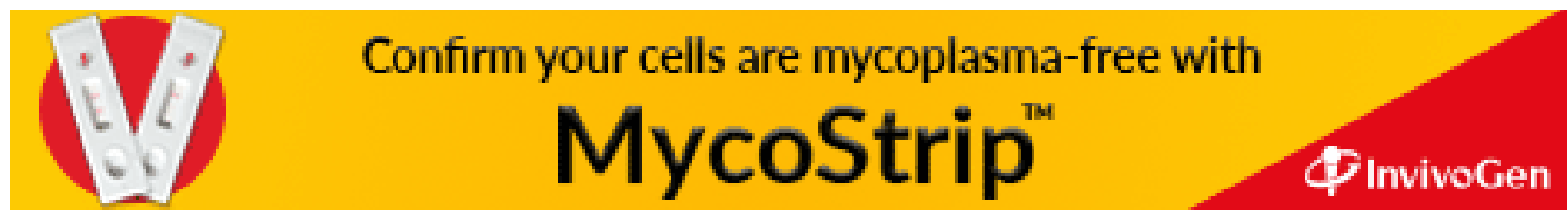

